\title{
Desenvolvimento de uma Plataforma Tecnológica para Recolha, Armazenamento e Gestão de Informação Estratégica da Águas do Centro S.A.
}

\author{
Ricardo Rio ${ }^{1}$, Vasco N. G. J. Soares ${ }^{1}$, Alexandre Fonte ${ }^{1}$, Bruno Bogaz Zarpelão ${ }^{2}$ \\ ${ }^{1}$ Escola Superior de Tecnologia do Instituto Politécnico de Castelo Branco \\ Av. do Empresário - Campus da Talagueira, 6000-767 Castelo Branco, Portugal \\ ${ }^{2}$ Departamento de Computação - Universidade Estadual de Londrina (UEL) \\ Cx. Postal 10011 - 86057-970 - Londrina - PR - Brasil \\ ricardorio28@ipcbcampus.pt, vasco.g.soareseipcb.pt, adfeipcb.pt, \\ brunozarpelao@uel.br
}

\begin{abstract}
This paper presents the development of a technological platform for the company Aguas do Centro SA, which permits the collection, storage, and management of strategic information. The computer solution based on opensource technologies was developed according to the ICONIX methodology. It is presented as a decision support system, which enables adding intelligence to management, providing greater competitiveness to the company.
\end{abstract}

Resumo. Este artigo apresenta o desenvolvimento de uma plataforma tecnológica para a empresa Águas do Centro S.A., que permite a recolha, armazenamento, e gestão de informação estratégica. A solução informática, baseada em tecnologias open-source, foi desenvolvida de acordo com a metodologia ICONIX. Apresenta-se como um sistema de suporte à decisão, que possibilita agregar inteligência à gestão, proporcionando maior competitividade à empresa.

\section{Introdução}

A Águas do Centro S.A. [Águas do Centro 2014] é uma Sociedade Anónima de direito privado e capitais públicos criada pelo Decreto-Lei n. ${ }^{\circ} 197-A / 2001$, de 29 de junho, situada em Castelo Branco, Portugal. É responsabilidade da empresa a exploração e gestão, as quais abrangem a conceção, a construção das obras e equipamentos, bem como a sua exploração, reparação e manutenção, do Sistema Multimunicipal de Abastecimento de Água e de Saneamento de Raia, Zêzere e Nabão, para a captação tratamento e distribuição de água para consumo público e para recolha, tratamento e rejeição de efluentes dos seguintes municípios portugueses: Alvaiázere, Castanheira de Pera, Castelo Branco, Ferreira do Zêzere, Figueiró dos Vinhos, Idanha-a-Nova, Oleiros, Pampilhosa da Serra, Pedrógão Grande, Proença-a-Nova, Sertã, Tomar e Vila Velha de Ródão.

A Águas do Centro fornece ainda água para consumo humano à Águas do Zêzere e Côa, S.A. e Águas do Mondego, S.A. para abastecimento ao sul do Fundão e parte de Ansião, respetivamente, e fornece serviços de tratamento de águas residuais à Águas do Mondego, S.A. para parte do município de Ansião. A partir de 2010 a 
Sociedade passou a abranger os Municípios de Entroncamento, Mação, Sardoal e Vila Nova da Barquinha.

Uma vez que a informação é um elemento chave para o sucesso na gestão da organização, a Águas do Centro, S.A. identificou a necessidade do desenvolvimento de uma solução informatizada integrada, que deverá dar suporte à recolha, armazenamento e gestão de informação estratégica relativa a consumos de energia, caudais, questionários internos e reclamações. $\mathrm{O}$ trabalho descrito neste artigo surge assim no contexto de um projeto aplicado desenvolvido no Mestrado de Desenvolvimento de Software e Sistemas Interactivos da Escola Superior de Tecnologia do Instituto Politécnico de Castelo Branco (ESTCB) [Rio, Soares, and Fonte 2014].

Pretende-se com este artigo descrever uma plataforma tecnológica desenvolvida de acordo com a metodologia ICONIX, e assente nas tecnologias de uso livre HTML, PHP, JavaScript, jQuery e MySQL, que dão resposta aos seguintes requisitos:

- Armazenamento da informação num único sítio, de forma consistente e robusta e que facilite a partilha da mesma entre setores/departamentos, de modo a resolver o problema da dispersão de dados e utilização partilhada de folhas de cálculo.

- Gestão da informação de caudais, permitindo a elaboração de relatórios dos consumos de cada município nos pontos de leitura dos caudais;

- Gestão da informação dos consumos de energia, permitindo a criação de análises e relatórios, auxiliando na interpretação de custos e quantidades consumidas por central de energia;

- Gestão e acompanhamento de reclamações de clientes;

- Gestão de questionários sobre normas de segurança.

Esta plataforma visa auxiliar de forma integrada os colaboradores da empresa nos processos específicos da sua atividade. Permite aos gestores estarem permanentemente informados sobre a situação da organização, garantindo-lhes o acesso a informação fiável que facilita a tomada de decisões informadas. Contribui para a redução de custos operacionais.

Este artigo encontra-se estruturado da seguinte forma. $\mathrm{Na}$ segunda secção, apresenta-se uma visão geral sobre os requisitos da aplicação. Na terceira secção, é discutida a metodologia de desenvolvimento adotada. De seguida, na quarta secção, apresenta-se a aplicação. Finalmente, na quinta secção, apresentam-se as conclusões e trabalho futuro.

\section{Visão geral da aplicação}

A aplicação informática desenvolvida assenta num conjunto de módulos que satisfazem de uma forma integrada os requisitos da empresa. Atualmente, os colaboradores utilizam um conjunto de folhas de cálculo, ferramentas e utilitários dispersos, de difícil perceção, integração e manutenção, para fazer face aos mesmos. Nas secções seguintes apresenta-se, para cada módulo, uma descrição do problema e os requisitos funcionais e não-funcionais do mesmo. 


\subsection{Módulo de gestão da informação de caudais}

Um colaborador da empresa é responsável por mensalmente registar os valores das leituras de todos os contadores nos pontos de leitura dos caudais. Esses valores são depois enviados para o departamento em causa, para que outro funcionário os insira numa folha de cálculo. Esta folha de cálculo, elaborada anualmente, contém os registos de todos os meses para cada um dos pontos de leitura. A partir destes registos, mensalmente, e de forma manual, é elaborado um documento para cada município, com os valores recolhidos nos caudais correspondentes. Estes resultados permitem a elaboração das faturas. No final de cada ano, a informação recolhida permite realizar estatísticas internas sobre os consumos de cada ponto de leitura e de cada município. Para esse efeito, os valores são copiados para uma nova folha de cálculo, criando-se os gráficos necessários.

São requisitos deste módulo o suporte à gestão de caudais, captados ou recolhidos, tratados, e fornecidos, por ponto de entrega/recolha, sistema e município, por forma a dispor-se de informação sobre a evolução dos mesmos, por meses e por ano, e remeter para faturação. Após a seleção de um município, deverá ser possível a geração de tabelas e gráficos com os valores dos pontos de entrega em questão, e permitir também a exportação dos mesmos para uma folha de cálculo ou arquivo no formato PDF.

\subsection{Módulo de gestão da informação dos consumos de energia}

Um colaborador da empresa é responsável por mensalmente, inserir os dados dos consumos de energia ativa e reativa, de todas as centrais de energia. Para esse efeito utiliza as faturas do fornecedor de energia, disponíveis sobre a forma de um arquivo XML. O colaborador tem de manualmente percorrer o conteúdo do arquivo XML à procura dos valores para copiá-los para uma folha de cálculo. A partir destes registos, mensalmente, e de forma manual, é elaborada uma análise de custos e uma análise de quantidades de $\mathrm{kW}$ que foram consumidos nesse período, para todas as centrais de energia. No final de cada ano, a informação recolhida permite realizar relatórios internos de cada central de energia, sobre os custos e as quantidades de energia consumidas, e calcular rácios de consumos de energia por metro cúbico. Para esse efeito, os valores das energias ativas e reativas são copiados para uma nova folha de cálculo, e é solicitado ao departamento dos caudais que disponibilize a sua folha de cálculo com os valores das leituras, para extrair os metros cúbicos consumidos por cada ponto de leitura. Relacionam-se estes valores com a central de energia e criam-se os gráficos necessários.

São requisitos deste módulo o suporte à gestão dos consumos de energia, por ponto de consumo, por forma a dispor-se de informação sobre a evolução dos consumos - energia ativa e reativa ao longo dos meses do ano - e comparar com meses homólogos do ano anterior e com os caudais, captados, tratados, elevados, etc. Para economia de recursos, e minimizar erros, pretende-se que os dados sejam diretamente importados do arquivo do fornecedor de energia. Deverá ser possível a importação dos dados contidos no arquivo XML para a base de dados, de forma automática, e a geração de tabelas de gráficos com os valores, permitindo a exportação dos mesmos para uma folha de cálculo. 


\subsection{Módulo de gestão e acompanhamento de reclamações de clientes}

Quando chega à empresa uma reclamação de um cliente, um dos seus colaboradores é responsável por inserir manualmente essa informação numa folha de cálculo, e averiguar o motivo da reclamação, contactando o departamento responsável. A empresa tem de respeitar uma regra imposta pelo regulador e avaliada pela Entidade Reguladora dos Serviços de Águas e Resíduos (ERSAR), que estipula que no prazo máximo de 22 dias úteis, o cliente terá de ser notificado com uma resposta. Como os dados estão numa folha de cálculo, sem automatismos ou mecanismos de notificação, é o colaborador o responsável por assegurar que o prazo de resposta não seja ultrapassado. No final de cada ano, a informação recolhida permite realizar estatísticas internas sobre os assuntos que tiveram mais reclamações, o número de reclamações de cada cliente, e o prazo de resposta das reclamações. Para esse efeito, através da folha de cálculo com o registo das reclamações, são criados os gráficos necessários.

São requisitos deste módulo o suporte à gestão do processo interno das reclamações, desde a sua receção até à resposta ao reclamante e resolução, incluindo um sistema de alertas quanto ao cumprimento dos prazos estabelecidos. Após a inserção dos dados, deverá ser possível a gestão das tabelas, gráficos das reclamações e envio de emails automáticos, tais como alertas aquando da aproximação do prazo limite para resposta a uma reclamação.

\subsection{Módulo de gestão de questionários sobre normas de segurança}

Um colaborador da empresa é responsável por semestralmente realizar questionários em papel a todos os colaboradores sobre as normas de segurança no local de trabalho. A análise das respostas a estes questionários permite concluir se existe a necessidade de promover formação para os colaboradores da empresa. As respostas ao questionário, têm de ser copiadas manualmente para uma folha de cálculo, que permite depois a elaboração de um relatório e respetivos gráficos.

São requisitos deste módulo o suporte à gestão do processo interno dos questionários, desde a criação do questionário até à análise e estatísticas das respostas recolhidas. Após o término de um questionário, deverá ser possível a geração de gráficos com as respostas, e permitir também a exportação dos mesmos.

\section{Metodologia de desenvolvimento}

Para o desenvolvimento do sistema adotou-se a metodologia ICONIX [Engineering 2013], por se tratar de uma metodologia prática e simples, mas também poderosa com uma componente de análise e representação de problemas sólida e eficaz [Silva and Videira 2001]. O ICONIX utiliza a linguagem Unified Modelling Language (UML) [Unified Modeling Language 2014] para a modelação. Com recurso à notação UML foram descritos os diagramas de classes, os diagramas de casos de uso, os diagramas de robustez e os diagramas de sequência [Silva and Videira 2001].

Nas subsecções seguintes descreve-se brevemente as atividades executadas nas principais fases do ICONIX, as quais são ilustradas na Figura 1. Esta figura mostra também as visões dinâmica e estática do sistema, que vão sendo desenvolvidas incrementalmente e em paralelo [Tancredo and Cesconeto 2011]. O modelo da dinâmica

representa a interação do utilizador com o sistema. E o modelo da estática demonstra o funcionamento do sistema sem nenhum dinamismo e interação do utilizador. Toda a 
documentação produzida no âmbito deste processo encontra-se disponível em [Rio et al. 2014], sendo aqui brevemente ilustrada por motivo de limitação de espaço.

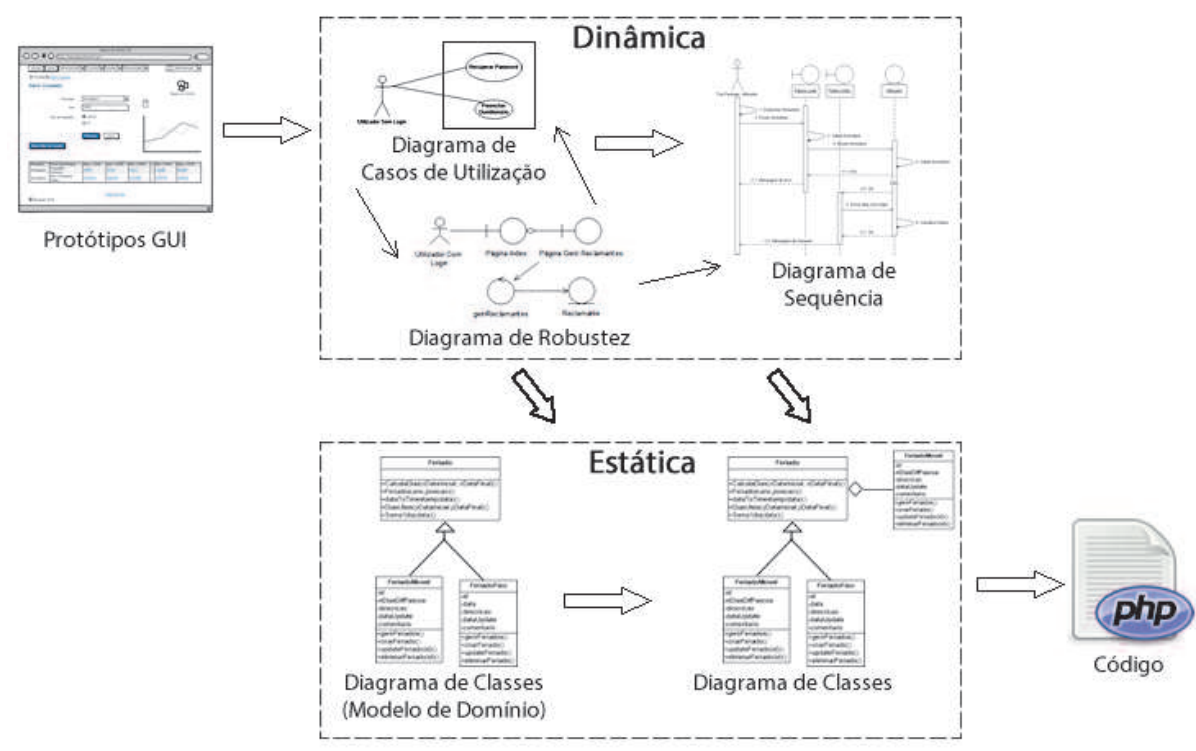

Figura 1 - Ilustração do modelo ICONIX.

\subsection{Análise de requisitos}

Nesta fase foram criados os diagramas de classes, o storyboard e os casos de uso. Os diagramas de classes foram utilizados para ilustrar graficamente os objetos necessários na construção da aplicação. Os storyboards permitiram ilustrar cada cenário e a navegabilidade da aplicação. A Figura 2 apresenta um exemplo de um storyboard com o ecrã que mostra a informação com os registos dos caudais. Os diagramas de casos de uso serviram para ilustrar graficamente os diferentes atores que iriam interagir com a aplicação e as ações que podem ser executadas por cada um deles. A Figura 3 ilustra os casos de uso de um utilizador registado.

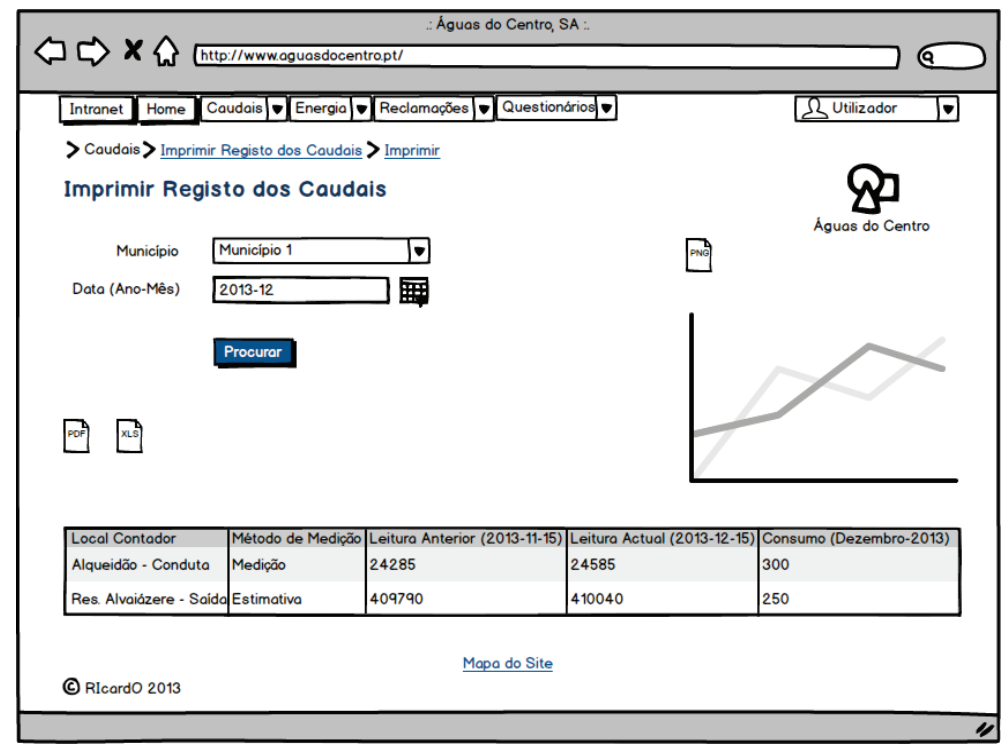

Figura 2 - Storyboard: ecrã para imprimir os registos dos caudais. 


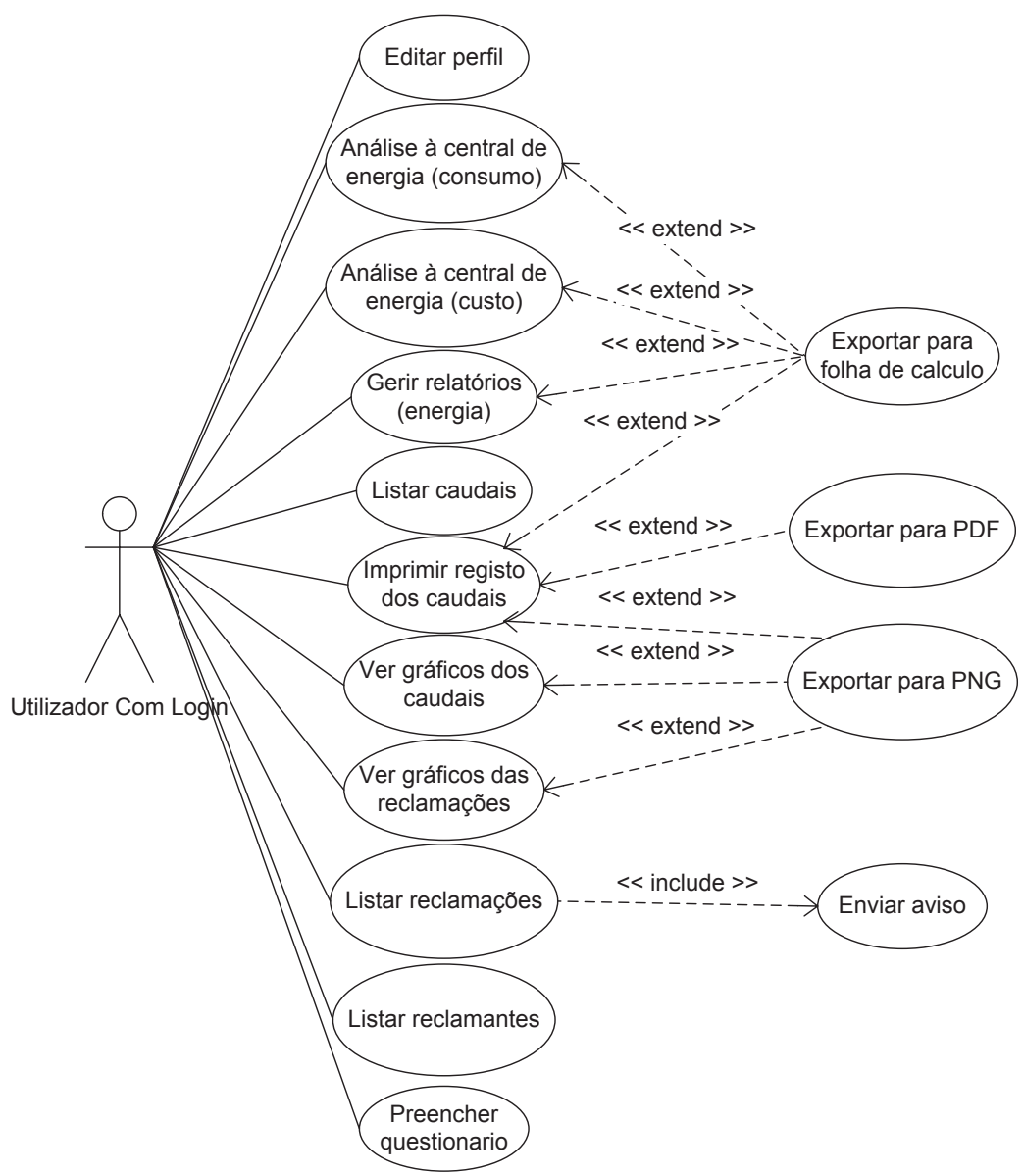

Figura 3 - Diagrama de casos de uso de um utilizador registado.

\subsection{Análise e desenho preliminar}

Nesta fase procedeu-se à descrição dos casos de uso, criação dos diagramas de robustez e criação da base de dados. Os diagramas de robustez foram construídos para ilustrar graficamente as interações entre os objetos e os casos de uso. Para a criação da base de dados foi elaborado o modelo de entidade-relacionamento e o modelo relacional, posteriormente implementado num Sistema de Gestão de Base de Dados (SGBD) MySQL. A Figura 4 ilustra uma vista parcial do modelo relacional proposto, omitindose as restantes tabelas e relacionamentos por uma questão de complexidade e limitação de espaço. 


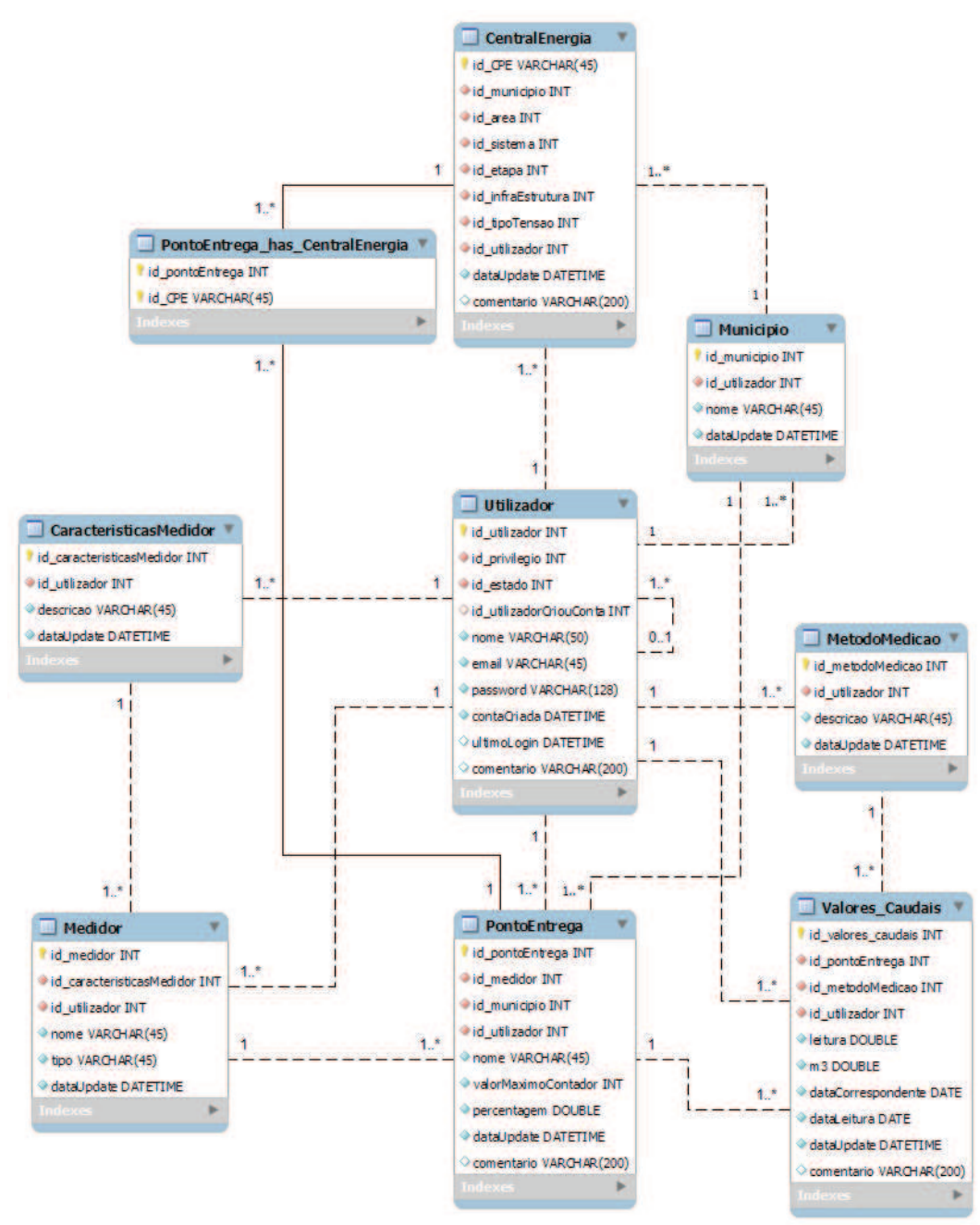

Figura 4 - Vista parcial do modelo relacional.

\subsection{Desenho}

Nesta etapa foi selecionada e desenhada a arquitetura da aplicação. Adotou-se um modelo de quatro camadas [Battisti 2003], devido a ser necessário uma camada para o armazenar e recuperar a informação a partir de uma base de dados, uma camada de lógica de negócio onde a aplicação é coordenada, os processos são executados, são tomadas decisões de lógica e realização de cálculos, e por fim, necessita-se de uma camada para apresentar a informação ao utilizador. Esta camada encontra-se subdividida em duas devido a tratar-se de uma aplicação web. Não é necessário executar a aplicação através de um terminal instalado no dispositivo do cliente, apenas existe a necessidade de um navegador para efetuar a ligação entre o dispositivo cliente e a camada de lógica.

Ainda nesta fase foram criados os diagramas de sequência com base no diagrama de classes e nos diagramas de robustez, de modo a haver um relacionamento entre os diagramas para que a modelação seja consistente e coerente. Os diagramas de sequência foram construídos para ilustrar graficamente os passos que os atores intervenientes necessitam de executar para realizar uma determinada ação. A Figura 5 
ilustra um exemplo de um diagrama de sequência para alterar o perfil do administrador/utilizador.

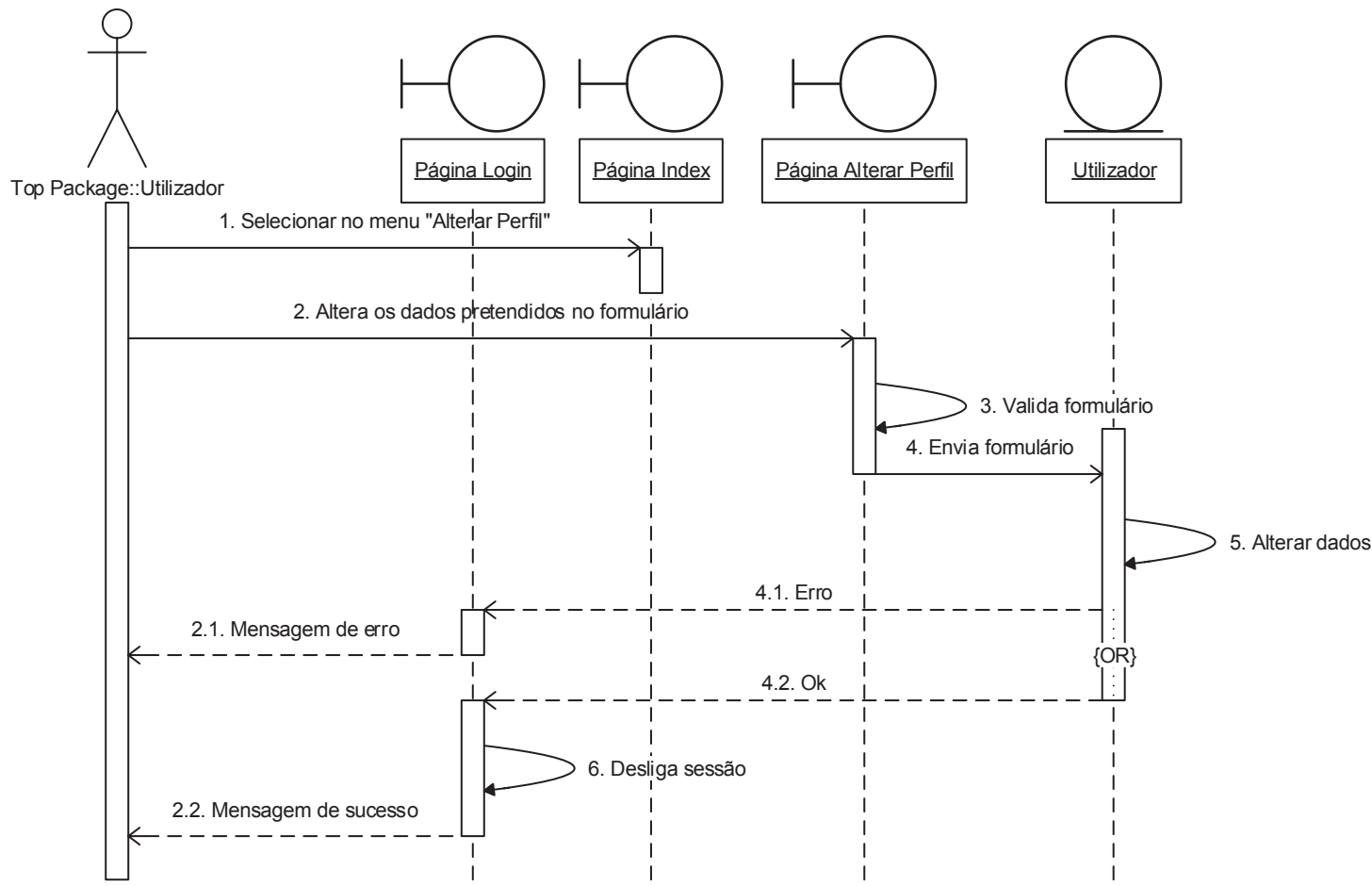

Figura 5 - Diagrama de sequência "Alterar perfil”.

\subsection{Implementação}

Nesta fase foi escrito o código da aplicação e realizaram-se os testes de integração e aceitação pela empresa. Para o desenvolvimento do código da aplicação foi necessário criar um ambiente de servidor local, para simular um ambiente web. Para isso foi instalado o WampServer (versão 2.4) que é um ambiente de desenvolvimento web para ambientes Microsoft Windows. Ele contém um conjunto de programas, como o Apache2 (versão 2.4.4), o PHP (versão 5.4.12), o MySQL (versão 5.6.12), entre outros, que são necessários para a simulação do servidor. O WampServer está disponível gratuitamente [WampServer 2013].

Com o ambiente de servidor local preparado, iniciou-se o desenvolvimento do código utilizando o programa Notepad++ (versão 6.5.2), o qual pode ser transferido gratuitamente em [Notepad++ 2011]. As linguagens que foram utilizadas para o desenvolvimento da aplicação foram: o PHP que é uma linguagem para desenvolvimento Web executada do lado do servidor, sendo embebida no HTML [Costa 2007]; o Javascript que é uma linguagem de script executada do lado do cliente, sendo interpretada pelo navegador web, e que permite a criação de páginas interativas [Costa 2007]; o jQuery que se trata de uma API em Javascript, rápida, pequena e rica em recursos, tornando o HTML e a manipulação de eventos, animações e Ajax muito mais simples e fáceis de usar [The jQuery Foundation 2014].

Por forma a garantir que aplicação estaria acessível a partir da Internet, permitindo, ao longo do tempo, o teste e avaliação dos módulos e funcionalidades desenvolvidas, por parte dos colaboradores da organização, alojou-se a mesma num servidor Scientific Linux 6, Apache 2.2, PHP 5.3 e MySq1 5.1. 


\section{Aplicação}

Novamente, por questões de limitação de espaço do artigo, são apresentadas, nesta secção, apenas algumas das funcionalidades disponibilizadas pela aplicação. O leitor interessado pode aceder e testar a mesma na íntegra a partir da hiperligação "https://projectos.est.ipcb.pt/aguascentro/index.php", utilizando como credenciais de acesso (login e password) de utilizador registado: "utilizador@aguascentro.pt" "123".

\subsection{Funcionalidades}

A aplicação desenvolvida preenche os requisitos acima descritos, estando preparada para ser executada em diferentes plataformas (i.e., desktop e móvel), adaptando-se a ecrãs de diferentes dimensões. A Figura 6 apresenta uma visão geral de todas as funcionalidades disponibilizadas.

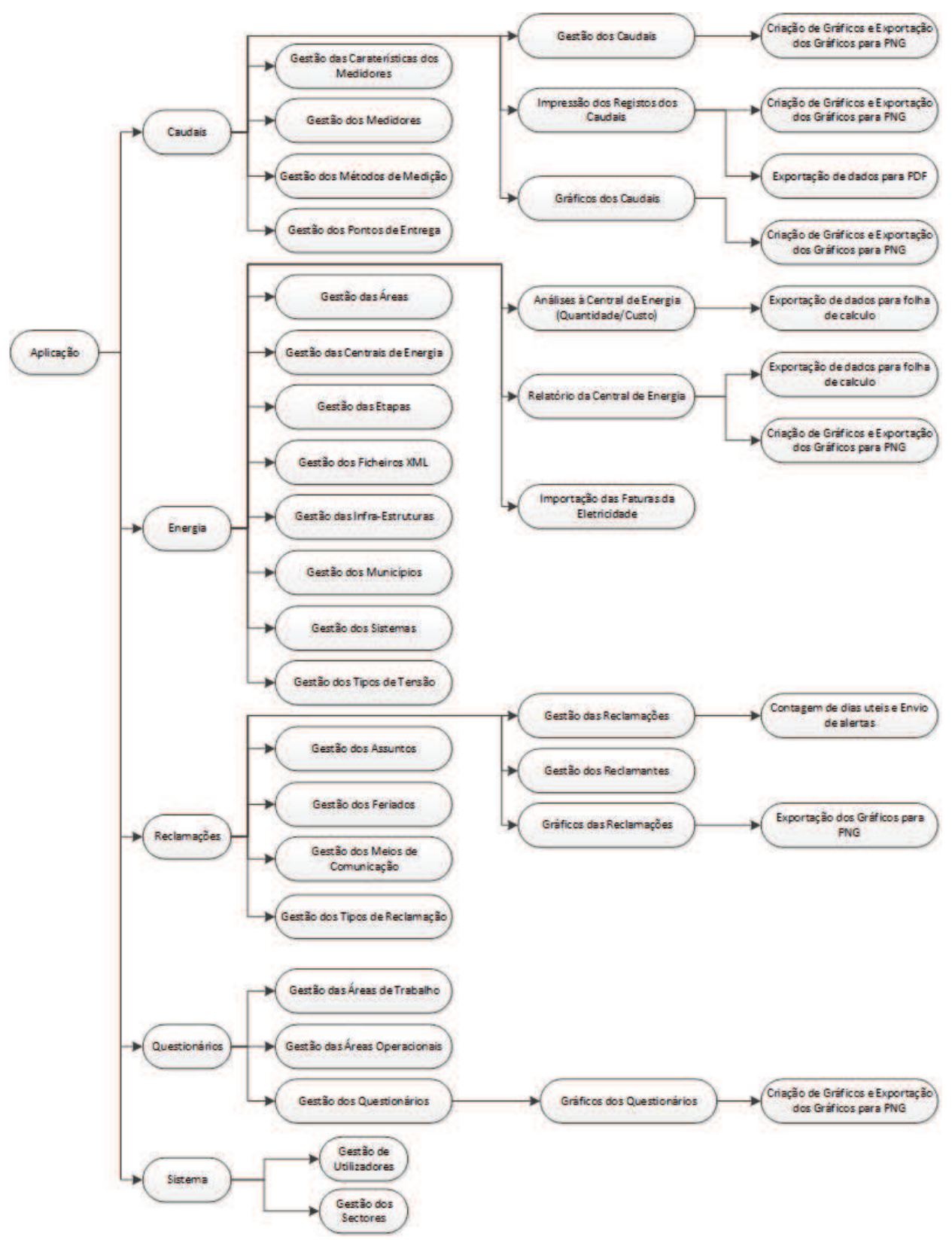

Figura 6 - Funcionalidades disponibilizadas pela aplicação. 


\subsection{Esquema navegacional}

O esquema navegacional, ilustrado na Figura 7 , foi definido a partir do modelo conceptual da aplicação e especifica a informação a ser apresentada aos diferentes tipos de utilizadores e a possível navegação.

Intranet Home Administrador - Caudais - Energia - Reclamaçỗes - Questionários - 2 Ricardo (Admin)

Figura 7 - Esquema navegacional do administrador.

A única diferença nos menus disponíveis ao utilizador "Administrador" e ao "Utilizador Registado", é a aba "Administrador" que permite ao administrador realizar a gestão de todos os módulos da aplicação. Aos utilizadores registados é associado um ou mais setores, com as respetivas permissões associadas.

$\mathrm{Na}$ aba "Caudais", é possível gerir os valores, imprimir os registos e visualizar gráficos dos caudais. $\mathrm{Na}$ aba "Energia", é possível visualizar análises às centrais de energia relativamente às quantidades e custos num determinado período, visualizar relatórios das centrais de energia e importar arquivos XML com os valores gastos. Na aba "Reclamações" é possível gerir as reclamações, os reclamantes e visualizar gráficos elaborados através das reclamações. $\mathrm{Na}$ aba "Questionários" é possível gerir os questionários. Finalmente, a aba "Perfil" permite alterar os dados do perfil do utilizador e efetuar o logout da aplicação.

As Figuras 8 e 9 permitem visualizar a aplicação a ser executada num smartphone e num computador. As figuras mostram o documento mensal, que é necessário imprimir, com todos os pontos de leitura de um município. Consegue-se visualizar uma tabela com os valores, com dois botões que permitem a sua conversão para formato PDF ou para uma folha de cálculo. Do lado direito é possível visualizar um gráfico que representa o valor que cada ponto de entrega tem na data selecionada e no mês anterior, permitindo a comparação entre eles.

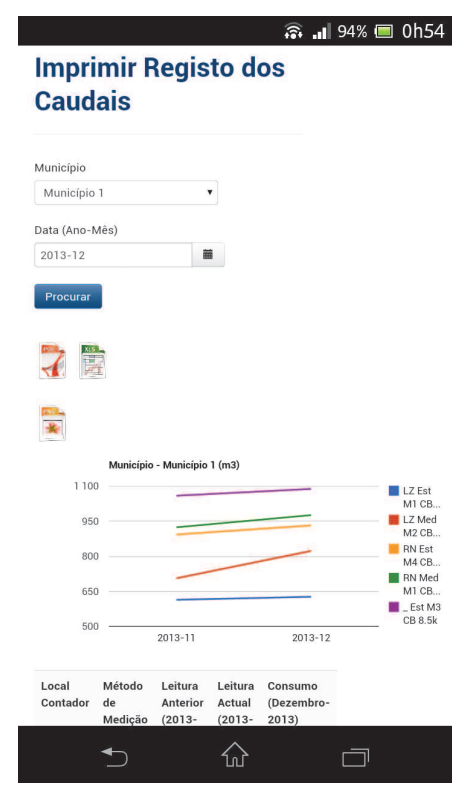

Figura 8 - Visualização da página "Imprimir Registo dos Caudais" através de um smartphone. 


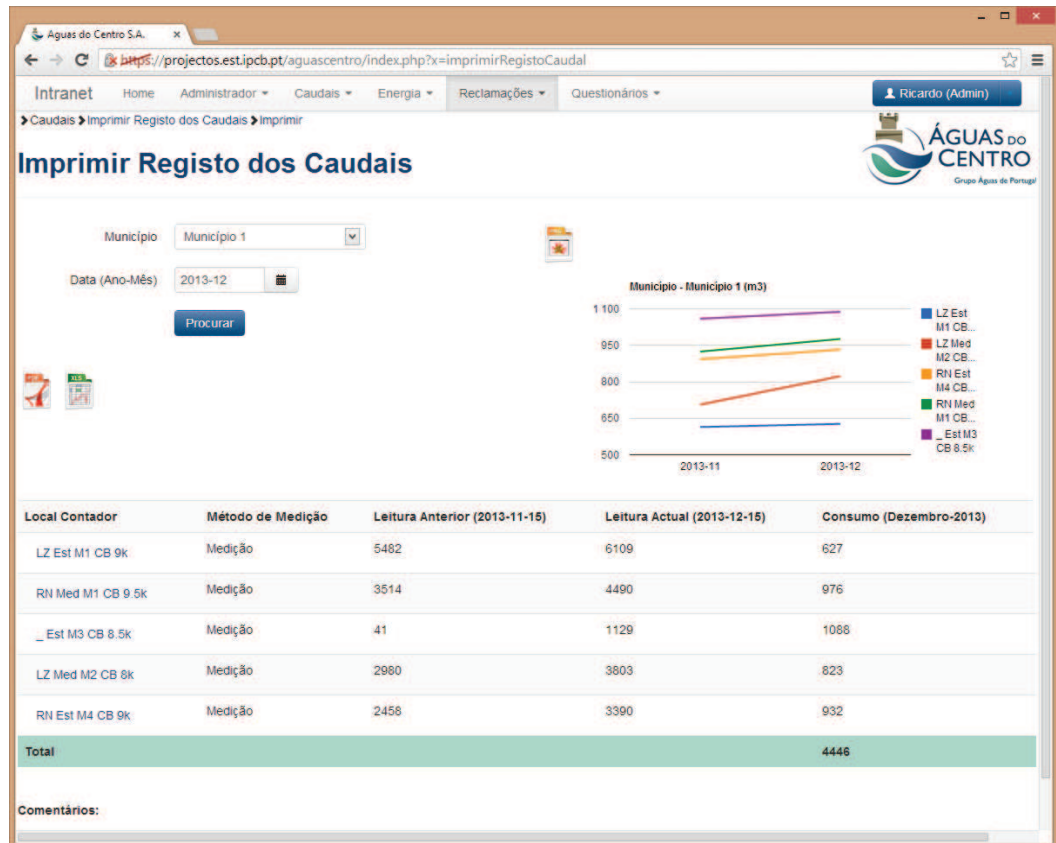

Figura 9 - Visualização da página "Imprimir Registo dos Caudais" através de um computador.

A Figura 10 mostra um exemplo de gráfico estatístico gerado no módulo de reclamações. Neste caso, o utilizador selecionou o ano pretendido, e foi gerado o gráfico com base nas reclamações recebidas nesse ano. É possível efetuar a conversão de qualquer gráfico para o formato PNG, bastando clicar no botão à esquerda do gráfico, com o símbolo correspondente.

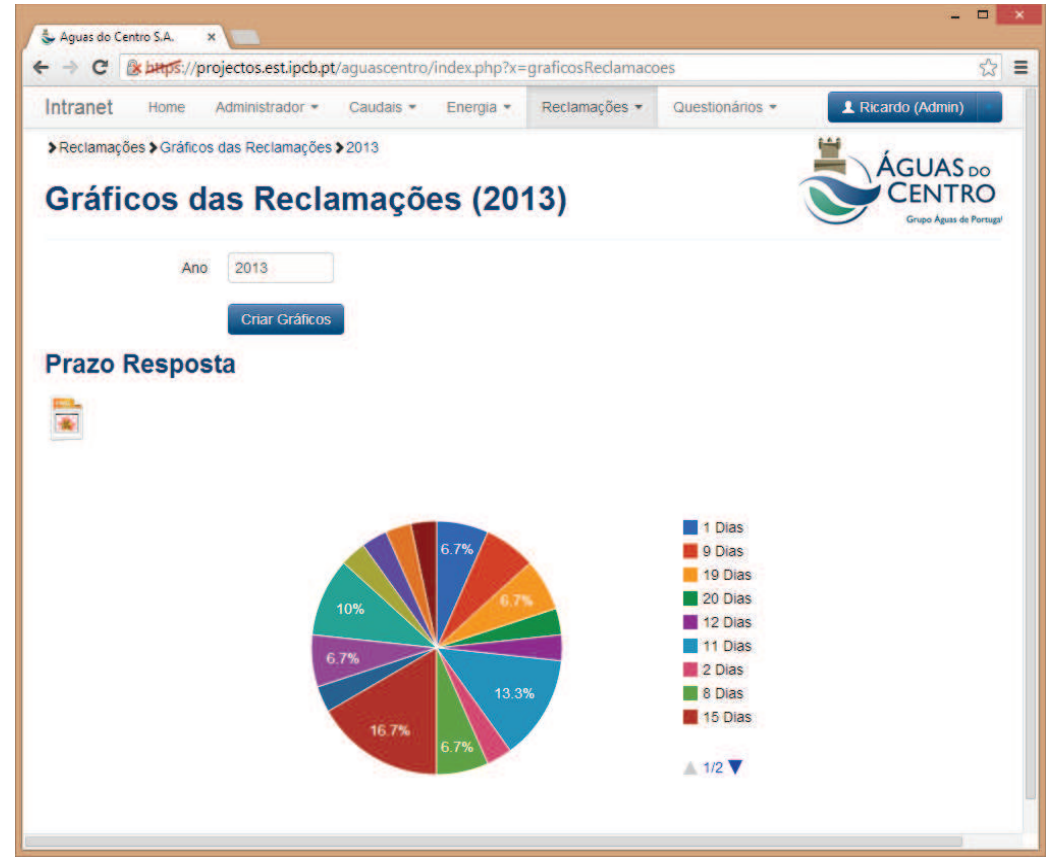

Figura 10 - Visualização de gráfico gerado no módulo de reclamações. 


\section{Conclusões e trabalho futuro}

Neste trabalho apresentou-se um projeto aplicado que culminou no desenvolvimento de uma plataforma tecnológica para suporte ao processo de recolha, armazenamento e gestão de informação estratégica para a empresa Águas do Centro S.A.. Com vista a reduzir o custo, o risco e o tempo do desenvolvimento do projeto e, também, aumentar a qualidade do produto final, foi adotada a metodologia de software ICONIX.

A solução final foi inteiramente desenvolvida com tecnologia aberta, de uso livre, sem custos para a organização. Permite substituir um leque de ferramentas e utilitários dispersos utilizados atualmente. Contribui para uma maior competitividade e redução de custos da empresa, otimizando o seu funcionamento, e auxiliando no processo de tomada de decisões, nos seguintes pontos específicos: gestão dos consumos de energia, gestão de caudais, gestão e acompanhamento de reclamações, e gestão de questionários internos.

A arquitetura modular e extensível da aplicação permite o desenvolvimento futuro de novas funcionalidades, algumas das quais potencializadas por outras já existentes. A aplicação já está em fase de testes e estará brevemente ao dispor de todos os colaboradores da empresa Águas do Centro S.A.

\section{Referências bibliográficas}

Águas do Centro, S. A. (2014). "Águas do Centro S.A.", http://www.aguasdocentro.pt/, Accessed 28/01/2014

Battisti, J. (2003). "Criando Aplicações em 3, 4 ou n Camadas", http://www.juliobattisti.com.br/artigos/ti/ncamadas.asp, Accessed 28/01/2014

Costa, C. J. (2007). Desenvolvimento para Web: Lusocrédito.

Engineering, I. S. (2013). "ICONIX Leaders in Object Tecnology", http://www.iconixsw.com/, Accessed 28/01/2014

Notepad++. (2011). "About", http://notepad-plus-plus.org/, Accessed 28/01/2014

Rio, R. and Soares, V. and Fonte, A. (2014). "Plataforma Para Recolha, Armazenamento e Gestão de Informação Estratégica da Águas Do Centro, S.A.", $\quad$ https://projectos.est.ipcb.pt/aguascentro/Relatorio.pdf, Accessed $29 / 01 / 2014$

Silva, A. and Videira, C. (2001). UML, Metodologias e Ferramentas CASE (1 ${ }^{\mathrm{a}}$ edição ed.). Portugal: Edições Centro Atlântico.

Tancredo, L. C. and Cesconeto, T. (2011). "Metodologia de desenvolvimento de software com ICONIX", http://pt.scribd.com/doc/56081208/Artigo-sobreICONIX, Accessed 20/02/2014

The jQuery Foundation. (2014). "What is jQuery?", http://jquery.com/, Accessed $29 / 01 / 2014$

Unified Modeling Language. (2014). "Unified Modeling Language (UML)", http://www.uml.org, Accessed 28/01/2014

WampServer. (2013). "WampServer", http://www.wampserver.com/en/, Accessed $28 / 01 / 2014$ 